\title{
Recent Advances in Experimental Testing and Computational Modelling For Characterisation of Mechanical Properties of Biomaterials and Biological Cells
}

\author{
V.B. Nguyen ${ }^{1}$, C.H. Le ${ }^{2}$, Z. Zhang ${ }^{3}$, R. Lee ${ }^{4}$, T. A. Nguyen ${ }^{5}$ and M.S. Packianather ${ }^{6}$ \\ ${ }^{1}$ College of Engineering and Technology, University of Derby, Derby, United Kingdom \\ ${ }^{2}$ Faculty of Engineering and Science, University of Greenwich, London, United Kingdom \\ ${ }^{3}$ School of Chemical Engineering, University of Birmingham, Birmingham, United Kingdom \\ ${ }^{4}$ School of Applied Sciences, London South Bank University, London, United Kingdom \\ ${ }^{5}$ Le Quy Don Technical University, Ha Noi, Viet Nam \\ ${ }^{6}$ School of Engineering, Cardiff University, Cardiff, United Kingdom
}

\begin{abstract}
Biomaterials and biological cells possess a number of different properties; amongst them, mechanical properties are extremely important in studies and applications about tissue engineering, design and development of implants, surgical tools and medical devices for treatments and diagnosis of diseases. Changes in mechanical properties such as a stiffness of cells are often the signs of changes in cell physiology or diseases in tissues; and studying these changes can lead to the development of devices for early disease detection and new drug delivery mechanisms. This paper presents advances in recent years in experimental testing and computational modelling for characterisation of mechanical properties of biomaterials and biological cells, in which the presented research projects and related studies were mainly implemented by research groups in the UK. The recent important findings as well as research directions and challenges are emphasised and discussed, to open channels for research collaborations in development of cost-effective medical diagnosis and treatment solutions.
\end{abstract}

Keywords - Biomaterials, biological cells, experiment, computational modelling, finite element analysis (FEA).

\section{INTRODUCTION}

Biomaterials have been widely used in medical applications, not only for replacements of injured or diseased tissues, but also for development of medical devices and tools. Especially, biomaterial engineering, in combination with biological tissues and cell technologies, have been playing a very important role in the areas of biomedical engineering and tissue engineering, to develop novel strategies to combat life threatening diseases, and to improve the existing healthcare facilities [1-3]. Biomaterials and cells possess a number of different properties; amongst them, mechanical properties are extremely important in studies and applications about tissue engineering, design and development of implants, surgical tools and medical devices for treatments and detection of diseases. In order to develop new ways to repair or replace damaged tissues and organs, researchers in tissue engineering must know the mechanical properties of both individual cells and tissues. In many applications, the material is exposed to mechanical forces at the sites at which it must function, such as compression in cartilage and bone replacements, tension in muscle and tendon substitutes or shear force in blood vessels. Additionally, diseases, like cancer, affect the mechanical properties of native cells. These forces also have a significant effect on the progression of mechanically related diseases. Changes in mechanical properties such as stiffness of cells are often the signs of changes in cell physiology or diseases in tissues; and studying these changes can lead to the development of devices for early disease detection and new drug delivery systems. To characterise the mechanical properties of biomaterials and cells, a wide variety of tools have been adapted from the physical sciences. These tools include experimental testing that helps elucidate the mechanical properties of materials, the nature of cellular forces, and the biological responses of cells under the external forces. These experimental tests and results could be mathematically modelled by computational modelling technologies with appropriate constitutive models for the cell materials. These models have been advantageous in explaining the experimental observations or predicting the system behaviour by providing a framework of underlying cellular mechanisms.

This paper presents advances in recent years in experimental testing and computational modelling for characterisation of mechanical properties of biomaterials and biological cells, in which research groups in the UK mainly implemented the presented research projects and related studies. The rest of the paper is organised as follows. Section II and III present the issues about methods and technologies for experimental testing and computational modelling used to characterise mechanical properties of biomaterials and biological cells. Finally, discussions and conclusions are presented in Section IV, with the highlights of the research in characterisations of the mechanical properties of biomaterials and cells in the UK in recent years.

\section{EXPERIMENTAL TESTING FOR CHARACTERISATION OF MECHANICAL PROPERTIES}

The mechanical properties of biomaterials and cells have been studied extensively using various experimental techniques. In general, there are two different types of tools used for characterising the mechanical properties of biomaterials 
and biological cells. The first type is based on forceapplication techniques, which apply a force directly to the material and then record the material's biomechanical response to this force. The second type is that of force-sensing techniques (usually used for biological cells), which seed cells onto deformable structures to measure their traction forces. Details of these techniques can be found in [4]. Generally, the choice of experimental technique is based upon what size or type of biological structure that is being investigated, what type and magnitude of loading and deformation of the material being observed, and what specific information is desired regarding that structure, i.e., microscale structures require microscale tools, whereas nanoscale structures require nanoscale tools. Recently, advances in technology have allowed for the development of a number of different specialized techniques. A review of 45 experimental studies (based on 45 references cited in [4]) on various types of biological cells has revealed that $38 \%$ of the studies used the atomic force microscope (AFM) technique; $18 \%$ used the compression technique; $11 \%$ used microneedle technique; $9 \%$ used micropipette aspiration technique; $7 \%$ used stretch technique; and very small percentage, less than 5\%, for other techniques such as particle tracking, magnetic twisting cytometry and optical tweezers. Therefore, in this paper only some of the most common and seminal techniques are reviewed and discussed. They include atomic force microscope, micropipette aspiration and compression-based manipulation techniques.

\section{A. Atomic force microscope (AFM)}

It uses a flexible cantilever with a fine tip at its free end, to probe cellular structures [5-6]. The tip is directed downward by a piezoelectric stage to probe a sample. The tip displacement is tracked by a laser and has excellent measurement precision, as shown in Fig. 1(A).
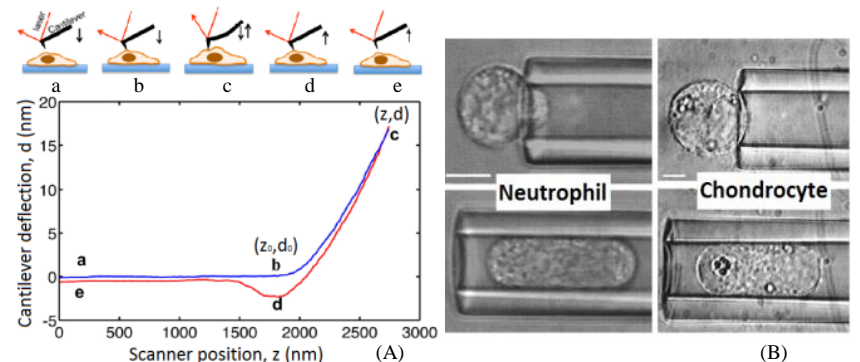

Fig. 1 (A): Illustration of AFM and interpretation of the force curve [6].

(B): Illustration of a neutrophil and a chondrocyte each being aspirated into a micropipette. The scale bars indicate $5 \mu \mathrm{m}$ [9]

The cantilevers are designed as elastic beams so that their deflection is proportional to the force applied to the cell. The portion of the force curve from point $b$ to point $c$ in Fig. 1(A), where the tip indents into the cell, fits into an elastic model to extract the cell stiffness. The AFM techniques have been widely applied to characterise the micro- scale stiffness for a variety of biomaterials and soft biological tissues and cells. It has force application range of $10-10^{3}$ $\mathrm{pN}$; it can provide rich data at one discrete point of a cell at a time, but is limited in probing multiple points of a cell with high temporal resolution. Scanning with too higher force can damage the cell; deformation in cells may not reflect the true sample topography, but rather represents the interaction of the probe with the sample surface as it depends on the AFM tip. In addition, deformation to the cell membrane often occurred without any applied force and this can result in an overestimation of the force-indentation curve and subsequently the elastic modulus of the cell [7].

\section{B. Micropipette aspiration}

This technique is often used to study whole-cell mechanics through micropipette suction in which the surface of a cell is aspirated into a small glass tube while tracking the leading edge of its surface [8-9]. Video microscopy is generally used to monitor the volume of cell material outside the pipette by tracking the radius of this material, as well as the length of cellular material within the glass pipette. Both soft cells, such as neutrophils and red cells, and more rigid cells, such as chondrocytes and endothelial cells, are studied with this technique, as illustrated in Fig. 1(B). Interpretation of the measurements with basic continuum models leads to values for a cell's elastic and viscous properties.

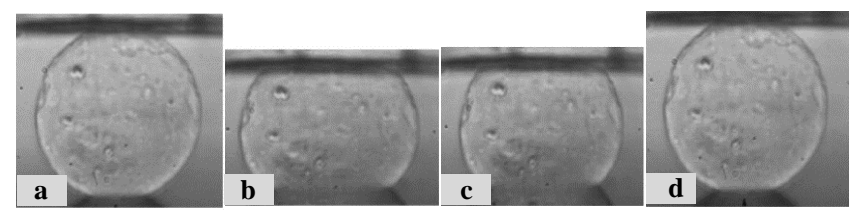

Fig. 2 A single alginate microsphere being compressed between two flat surfaces: (a) before compression; (b) during compression, at the beginning of relaxation; (c) during compression, at the end of relaxation and (d) after compression and full recovery [10]. Cell diameter of $100 \mu \mathrm{m}$

Micropipette aspiration has some advantages including its relative simplicity and low cost with comparison to other methods. Its range of suction pressures, from $0.1 \mathrm{pN} / \mu^{2}$ to almost atmospheric, and forces, from about $10 \mathrm{pN}$ to 104 $\mathrm{nN}$, is unsurpassed by other techniques, and the large range of soft cells that can be studied using this technique. However, this technique is limited in spatial resolution to the micron scale, deforms and possibly damages the cell to a large degree during testing, and its accuracy is based on optical imaging limitations.

\section{Compression manipulation}

The basic principle of the compression manipulation techniques is the compression of a single particle (for example, a cell in a medium) or a population of cells between two parallel surfaces [10-11]. These are usually the flat end of a glass probe and the bottom surface of a sample chamber or a 
microscope slide surface. Fig. 2 shows a single alginate microsphere being compressed. As the probe is driven by a micromanipulator towards the slide, a transducer measures the force being imposed on the particle. A forcedisplacement curve can be generated from the data. This technique has some advantages such as the wide range of different stimulation profiles that are possible, as well as the ability to study either single cells or cell populations for large forces, from biomaterials to biological cells such as chondrocytes [12]. Unlike other methods, large deformations are possible, including to bursting of cells. However, the Poisson-effect leads to anisotropy in the applied strain field, and there is strain heterogeneity at the specimen-plate interface [13].

\section{COMPUTATIONAL MODELLING FOR CHARACTERISATION OF MECHANICAL PROPERTIES}

Experimental tests provide crucial data but often do not offer a clear interpretation for characterising mechanical properties of biomaterials and cells, i.e. to identify what is the mechanism of the material's response to mechanical stimuli. In addition, experimental testing alone is limited due to complex cell geometries, complex boundary conditions, the nonlinear and inhomogeneous nature of a cell's materials and structures, cell remodeling over time, and the active response of the cell to mechanical stimuli that are applied as part of the measurement process. Today, computational modelling has been widely used to represent cellular mechanics and characterize material properties, and there are two principal types, namely structure-based models and continuum models. However, the main category of computational modelling is continuum models so this review focused on these models. Continuum models are generally solved using the finite element method. To extract the biomechanical properties of materials, experimental compression data must be mathematically modelled using an appropriate constitutive model for the cell material. They include linear elastic, hyperelastic, biphasic (or poroelastic) and viscoelastic models. Both elastic and viscoelastic models have been used extensively for simulation of cells under compression $[14,15]$ and a more complex linear biphasic model has been applied to cell-surrounding pericellular matrix interactions [16]. In these elastic and viscoelastic models, the cell has been assumed to be an isotropic, homogeneous, linear elastic or viscoelastic solid, and in most cases, it was assumed that the material of the cell is incompressible.

It is also generally assumed that the strain generated during compression is small so that linear elastic or viscoelastic models could be applied. However, if a cell is compressed to large cell deformations [11,17], large strains (e.g. $5 \%$ or more) might be generated and nonlinear elastic or viscoelastic models should then be preferable. In this case, suitable constitutive equations might be obtained by assum- ing that the cell is hyperelastic, in which case the stress components can be derived from an appropriate strain energy function. While there are many types of strain energy function that might be chosen for modelling, the neoHookean material model has been used successfully to describe nonlinear elastic behaviour of cells in compression experiments on endothelial cells [18] and eukaryotic cells [19]. However, biological cells were found to be viscoelastic at large deformations, and showed significant force relaxation after compression $[11,20]$. Therefore, a nonlinear viscoelastic model has to be developed to describe their behaviour at such deformations. These assumptions make it possible to characterize cell mechanical properties easily and to understand how the properties vary under different conditions. Fig. 3 shows an FE simulation using a hyperviscoelastic model for a microcompression test of a single chondrocyte cell.

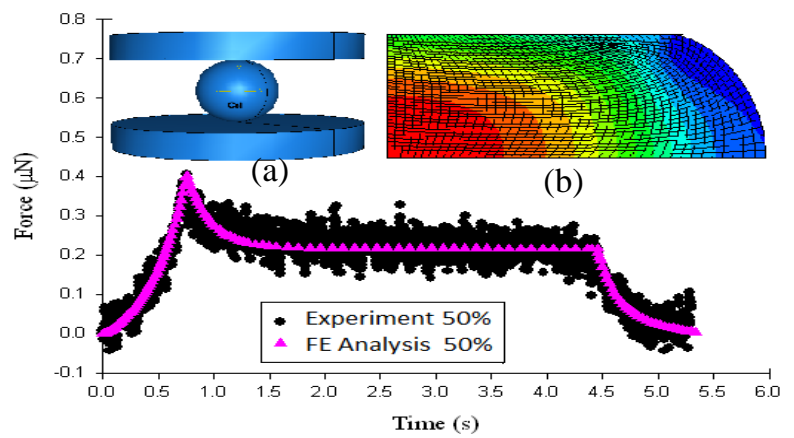

Fig. 3 Finite-element analysis to determine the mechanical properties of chondrocyte cells by matching with experimental results, showing (a) 3D

$\mathrm{CAD}$ and FE model, and (b) deformed cell at 50\% deformation [11]

In reality, cells are actually highly heterogeneous and anisotropic, with intracellular components (cytoskeleton, nucleus, cytoplasm and several other organelles) and these lead to complicated constitutive models. Such constitutive formulations require a large number of parameters that are highly nonlinear and consequently computationally expensive. The biggest challenges are that a model should be robust to predict a vast array of experiments and incorporate the bio-chemo-mechanical processes into the modelling solvers.

\section{DisUSSION AND CONCLUSION}

Understanding mechanical properties of biomaterials and biological cells are extremely important in studies and applications about tissue engineering, design and development of implants, surgical tools and medical devices for treatments, diagnosis, and early detection of diseases as well as new drug delivery mechanisms. In this paper, the important advances in recent years in experimental testing and computational modelling for characterisation of mechanical properties of biomaterials and biological cells are presented and briefly discussed, with the focus on our core research activi- 
ties in this area. In the UK, there are growing numbers of research projects and groups in biomedical engineering in general, and in biomaterials and cells' mechanics in particular. Table 1 presents briefly the active research groups in the UK and their research about characterisation of mechanical properties of biomaterials and biological cells, especially in the areas of tissue engineering, design and development of implants, surgical tools and medical devices..

Table 1 Active research groups in the UK in the area of characterisation of mechanical properties of biomaterials and biological cells

\begin{tabular}{|c|c|}
\hline RESEARCH GROUPS & RESEARCH \&APPLICATIONS \\
\hline $\begin{array}{l}\text { Biomedical Engineering } \\
\text { Research Unit, Aston } \\
\text { University }\end{array}$ & $\begin{array}{l}\text { - Bone fracture } \\
\text { - Medical implants } \\
\text { - Biological interactions } \\
\text { - Medical devices and implants }\end{array}$ \\
\hline $\begin{array}{l}\text { Biomedical Engineering } \\
\text { Research Group, Cardiff } \\
\text { Institute of Tissue Engineer- } \\
\text { ing, Cardiff University }\end{array}$ & $\begin{array}{l}\text { - Head injuries } \\
\text { - Bone fracture } \\
\text { - Tissue Engineering } \\
\text { - Medical devices and implants }\end{array}$ \\
\hline $\begin{array}{l}\text { Micromanipulation and } \\
\text { Microencapulsation Research } \\
\text { Group, University of Bir- } \\
\text { mingham }\end{array}$ & $\begin{array}{l}\text { Encapsulation for pharmaceutical, agro- } \\
\text { chemical and human care applications } \\
\text { - Cell mechanics and tissue engineering } \\
\text { - Medical devices and implants } \\
\end{array}$ \\
\hline $\begin{array}{l}\text { Bioengineering Science } \\
\text { Group, University of South- } \\
\text { ampton }\end{array}$ & $\begin{array}{l}\text { - Medical devices and implants } \\
\text { - Tissue Engineering } \\
\text { - Plant bioengineering } \\
\text { - Colloid processing } \\
\end{array}$ \\
\hline $\begin{array}{l}\text { Bioengineering Research } \\
\text { Group, University of } \\
\text { Manchester }\end{array}$ & $\begin{array}{l}\text { - Medical devices and implants } \\
\text { - Tissue engineering }\end{array}$ \\
\hline $\begin{array}{l}\text { The Institute of Biomedical } \\
\text { Engineering, Imperial } \\
\text { College }\end{array}$ & $\begin{array}{l}\text { - Medical devices and implants } \\
\text { - Musculoskeletal, cardiovascular, meta- } \\
\text { bolic, trauma, cancer } \\
\text { - Tissue Engineering }\end{array}$ \\
\hline $\begin{array}{l}\text { Biomechanical Engineering } \\
\text { Group, University of } \\
\text { Liverpool }\end{array}$ & $\begin{array}{l}\text { - Clinical practice in Ophthalmology } \\
\text { - Medical devices and implants }\end{array}$ \\
\hline $\begin{array}{l}\text { Biomedical Engineering } \\
\text { Research Group, University } \\
\text { of Greenwich }\end{array}$ & $\begin{array}{l}\text { - Medical devices and implants } \\
\text { - Tissue engineering } \\
\text { - Early detections of diseases }\end{array}$ \\
\hline
\end{tabular}

Recent improvements in experimental testing and computational models within the field of cell mechanics could help enhancing the quality of medical diagnosis and treatments, 3D printing of cells, or developing more effective medicines with new drug delivery mechanisms. For example, the mechanical behaviour of certain cells can potentially be used to quantify the cell's health, which could lead to the diagnosis of certain diseases that affect cell function. In addition, information regarding the difference between the mechanical behaviour of "healthy" and "unhealthy" cells can be used to predict whether therapeutic treatments will be effective in treating certain diseases.

Finally, a better knowledge of cell biomechanics, especially characterising the biomechanical properties, will enable improvements in biomechanics of tissues, which is essential in tissue engineering. These and other such potential applications of cell mechanics make it a very important topic of study, both currently, and for years to come; and these opens channels for research and technology development of cost-effective medical diagnosis and treatment solutions; especially, in combination with the recent innovations of micro and nano technologies, lab on chips and intelligent sensors can be developed for early detection of diseases.

\section{REFERENCES}

1. Hench LL (1980) Biomaterials, Science 208:826-831

2. Hench LL and Thompson I (2010) Twenty-first century challenges for biomaterials, J R Soc Interface 6-7:379-391

3. Bhat S and Kumar A (2013) Biomaterials and bioengineering tomorrow's healthcare, Biomatter 3(3):e24717 (12 pages)

4. Rodriguez ML et al. (2013) Review on cell mechanics: experimental and modeling approaches, Appl Mech Rev 65(6):060801 (41 pages)

5. Binnig G, Quate CF, Gerber C (1986) Atomic force microscope, Phys Rev Lett 56:930-934

6. Thomas G et al. (2013) Measuring the mechanical properties of living cells using atomic force microscopy, J Vis Exp 76:e50497

7. Addae-Mensah KA and Wikswo JP (2008) Measurement techniques for cellular biomechanics in vitro, Exp Biol Med 233:792-809

8. Mitchison JM and Swann MM (1954) The mechanical properties of the cell surface-the unfertilized sea-urchin egg, J Exp Biol 31:461-472

9. Jones WR et al. (1999) Alterations in the Young's modulus and volumetric properties of chondrocytes isolated from normal and osteoarthritic human cartilage, J Biomech 32:119-127

10. Nguyen VB et al. (2009) Mechanical properties of single alginate microspheres determined by microcompression and finite element modelling, Chem Eng Sci 64:821-829

11. Nguyen VB et al. (2010) Biomechanical properties of single chondrocytes and chondrons determined by micromanipulation and finite element modelling, J R Soc Interface 7:1723-1733

12. Wang QG et al. (2009) Gene expression profiles of dynamically compressed single chondrocytes and chondrons, Biochem Biophys Res Commun 379:738-742

13. Brown TD (2000) Techniques for mechanical stimulation of cells in vitro: a review, J Biomech 33:3-14

14. Guilak F et al. (2002) The effects of osmotic stress on the viscoelastic and physical properties of articular chondrocytes, Biophys J 82:720727

15. Leipzig ND, Athanasiou KA (2005) Unconfined creep compression of chondrocytes, J Biomech 38:77-85

16. Lee B et al. (2010) Dynamic mechanical properties of the tissueengineered matrix associated with individual chondrocytes, J Biomech 43:469-476

17. Shieh AC et al. (2006) Straindependent recovery behavior of single chondrocytes, Biomech Model Mechanobiol 5: 172-179

18. Caille N et al. (2002) Contribution of the nucleus to the mechanical properties of endothelial cells, J Biomech 35:177-187

19. Peeters EAG et al. (2005) Mechanical and failure properties of single attached cells under compression, J Biomech 38:1685-1693

20. Setton LA et al. (1993) The biphasic poroviscoelastic behavior of articular-cartilage: role of the surface zone in governing the compressive behavior, J Biomech 26:581-592

\footnotetext{
Author: Van Bac Nguyen

Institute: University of Derby

Street: Kedleston Road

City: Derbyshire

Country: UK

Email: VB.Nguyen@Derby.ac.uk
} 